\title{
Narcotráfico e Militarização nas Américas: Vício de Guerra*
}

Thiago Rodrigues**

\section{A Emergência de uma Guerra}

Há cem anos não havia narcotráfico. A maioria das drogas psicoativas que hoje são negociadas por traficantes e consumidas à margem da lei sequer era regulamentada, quanto mais proibida, o que significa que não havia ainda a definição da "questão das drogas" como um problema. No entanto, articulado sincronicamente no plano interno

\footnotetext{
* Artigo recebido em 31 de maio de 2012 e aprovado para publicação em 27 de agosto de 2012. ** Doutor em Ciências Sociais pela Pontifícia Universidade Católica de São Paulo (PUC-SP), professor no Departamento de Estudos Estratégicos e Relações Internacionais do Instituto de Estudos Estratégicos da Universidade Federal Fluminense (UFF) e pesquisador-colaborador no Núcleo de Sociabilidade Libertária da PUC-SP. Colabora com o GAPCon/UCAM e com a Coordinadora Regional de Investigaciones Económicas y Sociales (CRIES/Argentina). É ainda um dos fundadores do Núcleo de Estudos Interdisciplinares sobre Psicoativos (NEIP). E-mail: trodrigues@id.uff.br.
} 
de vários Estados e em incipientes foros internacionais, despontou, no início do século XX, um novo enfoque sobre as drogas psicoativas que acabou por iniciar a construção de um regime internacional de controle de drogas que agora, em 2012, completa seu centenário. A Conferência de Haia, de 1912, marco desse processo, produziu o primeiro tratado internacional nesse campo, que, no entanto, ainda não proibia a produção, venda e consumo de qualquer substância tampouco obrigava seus signatários a fazê-lo -, mas estabelecia uma inaugural intervenção sobre questões, até então, desregulamentadas. Atenção especial foi dedicada ao ópio e seus derivados, com o objetivo de limitar sua aplicação às chamadas finalidades médicas baseadas no juízo de que todo "uso não medicinal [de drogas] é patológico em si” (MCALLISTER, 2000, p. 17).

A recriminação do "uso recreativo" e a defesa estrita do "uso médico" eram, nessa época, o foco das discussões entre médicos e autoridades sanitárias nos Estados Unidos e em outros países nas Américas, Ásia e Europa. Ganhava força o argumento de que psicoativos como o ópio e a morfina alimentavam um problema de saúde pública que precisava ser enfrentado pela via do rigoroso controle dessas substâncias. A ojeriza ao uso de algumas drogas foi impulsionada e potencializada pelo vínculo anteriormente estabelecido entre algumas delas e determinados grupos de imigrantes e/ou minorias étnicas.

Nos EUA, esse vínculo, de corte xenófobo e racista, aconteceu com a maconha, identificada com hispânicos, o ópio com chineses, a cocaína com negros, o álcool com irlandeses e italianos; no Brasil, a heroína, por exemplo, tornou-se um problema de saúde pública quando, nos anos 1910, passou a ser tida como droga de cafetões e prostitutas, enquanto a maconha, vista como substância de negros capoeiras, era associada a um problema de ordem pública já no século XIX (RODRIGUES, 2004; PASSETTI, 1991). 


\section{Narcotráfico e Militarização nas Américas:}

Vício de Guerra

A somatória entre medos sociais, moralismo, xenofobia e racismo fortalecida pelas alegações no campo da saúde pública - catalisou clamores pela criminalização da produção e consumo de drogas. Nos Estados Unidos, a primeira grande vitória dos partidários da repressão às drogas e às pessoas associadas a elas foi a Lei Seca, aprovada em 1919 como uma emenda à Constituição estadunidense, que tornava ilegal todo o circuito de produção, comercialização e consumo de álcool. A proibição do álcool foi revogada em 1933, mas deixou, ao menos, dois importantes legados: o fortalecimento de grupos ilegais que se dedicaram ao seu tráfico, e o modelo proibicionista que, mesmo superado para o álcool nos anos 1930, foi estendido, a partir de então, a outros psicoativos como a cocaína e a maconha (PROVINE, 2007).

Desse modo, o proibicionismo - com sua combinação entre moralismo e repressão seletiva a certos grupos sociais - emergiu como uma das táticas de controle social que, na passagem do século XIX para o $\mathrm{XX}$, investiram na segurança das sociedades pela articulação de políticas punitivas e de intervenção sobre a vida e que procediam, por sua vez, de práticas de governo das populações que despontaram um século antes e foram chamadas por Michel Foucault (2003) de biopolíticas. Segundo o filósofo francês, o arcabouço jurídico-político da soberania, que despontou no final da Idade Média instituindo relações de força plasmadas no Estado e fundadas na centralidade e verticalidade do exercício do poder sobre um território e um conjunto de súditos, foi sobreposto e modificado a partir do surgimento de um novo problema de governo produzido nos inícios da era industrial: o problema da população.

A nascente indústria capitalista contemporânea provocou, na análise de Foucault, um afluxo de pessoas para os centros urbanos que era, simultaneamente, necessário para o funcionamento da economia e ameaçador para a própria ordem sociopolítica e econômica, na medida em que colocava desafios para a gestão do espaço urbano e para a 
contenção de revoltas e subversões. Para "administrar essa população" (FOUCAULT, 2008, p. 494), foram desenvolvidas - em países como a Alemanha, França e Inglaterra - políticas de medicina social voltadas tanto para a organização das cidades tendo em vista a sua salubridade e ordenamento espacial, quanto para a formulação de medidas específicas de atendimento da saúde das populações, com atenção para os grupos mais pobres e, potencialmente, mais perigosos (FOUCAULT, 1998). Essas políticas, segundo Foucault, inscreveram-se "no marco geral de uma 'biopolítica'; [que] tende a tratar a 'população' como um conjunto de seres vivos e coexistentes, que apresentam características biológicas e patológicas específicas" (FOUCAULT, 2008, p. 494) e que, por essa singularidade, exigiam a formulação de políticas para sua contenção, manutenção e controle.

A biopolítica seria, assim, um conjunto de práticas para o governo da vida das populações, compreendidas como tendo lógica e dinâmica próprias - taxas de natalidade, fecundidade, morbidade -, que demandariam investimentos e táticas de controle específicos. A população, desse modo, teria deixado ser a mera reunião de súditos do príncipe - como delineado pelo discurso político da soberania moderna - para ser um corpo vivo, um corpo-espécie, como coloca Foucault (2008), ao mesmo tempo necessário para o capitalismo e ameaçador ao poder político centralizado e ao regime da propriedade. Para manter a potência e força do Estado, da ordem social e do sistema capitalista, não bastava mais subjugar corpos e basear o exercício do poder no arbítrio do soberano sobre a vida e a morte dos súditos. Seria preciso, ao contrário, encontrar o delicado equilíbrio, o cálculo fino, entre aumentar a saúde e vigor físico de cada um sem que isso impulsionasse contestações à ordem. Essa sofisticada maquinaria de governo, atenta a cada indivíduo e ao conjunto deles, teria produzido, como analisa Foucault (2003, p. 383), modos contemporâneos de conduzir as condutas das pessoas destinados não apenas a matar, mas também a proporcionar um adicional de saúde e vida, uma “sobrevi- 


\section{Narcotráfico e Militarização nas Américas: Vício de Guerra}

da [...] uma vida melhorada". Desse modo, a intervenção do Estado na saúde geral das populações passou a ser, a partir da segunda metade do século XVIII, um dos campos principais para o exercício do poder político (FOUCAULT, 2008).

Entre os campos visados pelas táticas biopolíticas, seria possível localizar o controle sobre drogas psicoativas como um deles, abordado na sequência de medidas de governo sobre a vida e a conduta das pessoas que comporiam, já no princípio do século XX, o quadro amplo das intervenções sobre a população visando a gestão da vida por meio da determinação sobre que drogas se poderia ingerir, como, em que condições, com autorização de quem, sob a responsabilidade de quem.

Assim, as primeiras regulamentações sobre drogas - como a estadunidense "Food and Drug Act", de 1906 - foram normas sanitárias visando estabelecer parâmetros e vigilância sobre as condições higiênicas de produção de fármacos, sua rotulagem, embalagem e circulação. Anos depois, ainda nos EUA, veio o "Harrison Act", de 1914, que estabeleceu um controle mais rígido sobre o uso de psicoativos, baseado na antes mencionada finalidade médica. Somente com a proibição total de um conjunto de drogas psicoativas é que a questão sanitária e de saúde pública se converteu, também, em problema de segurança pública, amplamente lastreado nos juízos morais e racistas que demonizavam essas substâncias, quem as usava e as negociava. Desse modo, o controle de drogas, pautado pelo proibicionismo, poderia ser considerado uma potente tática biopolítica, pois, sincronicamente, permitiu a intervenção sobre hábitos individuais (uso de drogas para fins recreativos ou medicinais) - sob a justificativa de melhorar a vida individual e coletiva - e abriu espaço para a perseguição e apresamento de grandes contingentes de indivíduos tidos como perigosos à ordem social e que pertenciam, precisamente, às camadas mais pobres e numerosas dos centros urbanos que tanto preocu- 


\section{Thiago Rodrigues}

pavam e mobilizavam - desde finais do século XVIII na Europa e a partir do final do século XIX nas Américas - as classes governantes.

A proibição, todavia, não alcançou seu objetivo declarado: a supressão de hábitos relacionados a algumas drogas e de todo um circuito econômico a elas coligado. Ao contrário, acabou por impulsioná-lo às margens da lei. Assim, a "questão das drogas", que nos primeiros anos do século XX sequer existia como um "problema” social ou de saúde pública, em pouco mais de duas décadas se transformou em uma "ameaça às sociedades civilizadas". Em nome do combate a essa "ameaça", declarou-se uma guerra que, por sua vez, passou a retroalimentar esse suposto "perigo". Um dos efeitos imediatos foi o de que, no "regime da proibição, o valor das drogas seguiu extraordinariamente inflado, e esses produtos continuaram sendo vendidos em mercados ilegais muito acima de seus preços reais" (SERRANO; TORO, 2005, p. 242).

Na sombra produzida pela ilegalidade e criminalização, foi gerado o narcotráfico, negócio potente que expandiu e prosperou ao mesmo tempo em que se sofisticaram as leis domésticas e internacionais visando sua repressão. A cristalização internacional do regime proibicionista foi acompanhada não pela diminuição da economia das drogas ilícitas, mas pelo aumento global da demanda por psicoativos, principalmente após a Segunda Guerra Mundial (KOPP, 2006). O crescimento da demanda, a facilitação da circulação de produtos e pessoas com as inovações tecnológicas e dos meios de transporte no pós-1945, além do incentivo ao tráfico propiciado pelos lucros auferidos na ilegalidade, dinamizaram os fluxos de drogas ilícitas, internacionalizando efetivamente o problema. Assim, a partir dos anos 1950, emergiu um mercado ilícito de dimensões transterritoriais pari passu aos esforços para enrijecer o proibicionismo como estratégia para enfrentar aquilo que ele próprio produzira e impulsionara. 


\section{Narcotráfico e Militarização nas Américas: Vício de Guerra}

\section{Narcotráfico, Diplomacia e}

Guerra

O vetor biopolítico do proibicionismo não foi apenas produzido isoladamente no espaço jurídico-político dos Estados. Houve articulação e encadeamento entre a aprovação de leis domésticas cada vez mais restritivas à produção e uso de certos psicoativos e iniciativas diplomáticas, estimuladas pelos Estados Unidos, mas que contaram com a adesão de países americanos, europeus e asiáticos (MCALLISTER, 2000). Os encontros diplomáticos sobre drogas ganharam impulso após a Conferência de Haia, em 1912, e, principalmente, depois da Primeira Guerra Mundial (1914-1918). Primeiro, foram as reuniões e documentos produzidos pelo Comitê sobre o Ópio (Opium Board), nos anos 1920 e 1930, ainda sob a Liga das Nações, incorporados pela ONU após 1945 (FIDLER, 2001; HERSCHINGER, 2011). Em seguida, veio o trabalho para a padronização e universalização do regime de controle de drogas que acabou por acontecer com a assinatura da Convenção Única sobre Drogas, da ONU, em 1961.

Esse documento estabeleceu listas de psicoativos organizadas a partir do critério de "uso médico": as drogas consideradas com alguma aplicação médica, ainda que potencialmente geradoras de adição química, teriam uso legal assegurado; para as demais, deveria valer o banimento. A Convenção Única consolidou e universalizou a lógica proibicionista pautada na associação entre argumentos médico-sanitaristas e o objetivo de eliminação de todo uso que escapasse do controle estatal ou do estamento médico (FIORE, 2012). Para tanto, deveria persistir a criminalização de traficantes e usuários, além da expansão de medidas internacionais para combater o fluxo de psicoativos ilícitos.

O regime proibicionista de controle de drogas foi completado por outros dois tratados: a Convenção sobre Drogas Psicotrópicas, de 1971, 
que incorporou o LSD como uma substância a ser banida totalmente, e a Convenção das Nações Unidas contra o Tráfico Ilícito de Drogas Narcóticas e Psicotrópicas - também conhecida como Convenção de Viena -, assinada em 1988, que reafirmou o proibicionismo como política mundial para os psicoativos (MCALLISTER, 2000). Desde então, os documentos de revisão, elaborados pelas delegações dos Estados-membros da ONU coordenados pelo Escritório das Nações Unidas sobre Drogas e Crime (em inglês, United Nations Office on Drugs and Crime [UNODC]), com sede em Viena, não fizeram mais do que reforçar sua base proibicionista. De fato, "poucos governos contrapuseram desafios à abordagem proibicionista que orienta as três convenções internacionais" (INKSTER; COMOLLI, 2012, p. 6), o que faz do regime internacional de controle de drogas um raro consenso global a aproximar países que, na maioria das questões de política internacional, são antagônicos, como, por exemplo, os Estados Unidos e o Irã.

A diplomacia das drogas, cristalizada entre as décadas de 1960 e 1970, ganharia nessa mesma época a companhia de seu duplo: a guerra. Em 1972, o presidente estadunidense Richard Nixon veio a público anunciar que "as drogas" eram uma ameaça à sociedade estadunidense e que, para combatê-las, era necessário declarar uma "guerra às drogas" ("war on drugs"). O discurso da "guerra às drogas" baseou-se - e segue assim até hoje - na divisão estanque do mundo em dois blocos: o dos países produtores e dos países consumidores de drogas, dualismo fictício que ignora a dinâmica mais intrincada da produção e tráfico de psicoativos no mundo, que faz países como o Canadá e os EUA serem, desde os anos 1970, não apenas dois dos maiores consumidores globais de drogas, como também dois dos maiores produtores de maconha do mundo, assim como o Brasil, por sua vez, não é somente um "país de trânsito", como identificado nos anos 1980, mas também um dos maiores consumidores mundiais de cocaína (PASSETTI, 1991; GLENNY, 2008; UNITED NATIONS OFFICE ON DRUGS AND CRIME, 2012). 


\section{Narcotráfico e Militarização nas Américas: Vício de Guerra}

Ainda que maniqueísta e reducionista, o discurso da "guerra às drogas" permitiu aos EUA considerarem-se "vítimas" de grupos ilegais provenientes de outros países, externalizando as "fontes" de um problema para, assim, acionar uma retórica de segurança nacional que, na linha dos efeitos dos processos de securitização estudados por Buzan et al. (1998), permitiu, com ampla chancela da sociedade estadunidense, ações excepcionais em nome da defesa do Estado e da sociedade, tanto no plano interno (como o endurecimento das penas para traficantes e usuários, e consequente aumento do encarceramento) quanto no plano internacional, com intervenções policial-militares em países estrangeiros (RODRIGUES, 2003; HERSCHINGER, 2011).

Na sequência da declaração de Nixon, os EUA reformularam seu aparato repressivo, criando uma agência centralizadora do planejamento das ações antidrogas - a Drug Enforcement Administration (DEA), em 1974 - e dando início às primeiras operações contra o narcotráfico no Caribe e no México (RIBEIRO, 2000). Já no final dessa década, com o crescimento do tráfico de cocaína, as políticas antidrogas estadunidenses voltaram-se para os países andinos (Bolívia, Peru e Colômbia), fundamentadas na lógica de que o combate ao narcotráfico deveria ser conduzido pelo esforço coligado das polícias e Forças Armadas dos "países produtores". Para tanto, os EUA começaram a investir no treinamento e formação de grupos militares especiais, primeiro no México e, depois, nos países andinos (HARGRAVES, 1992).

Durante os governos de Ronald Reagan, a ênfase na militarização da "guerra às drogas" se acentuou. Nesse período, os EUA identificaram a associação entre guerrilhas de esquerda - como as Forças Armadas Revolucionárias da Colômbia (FARC) e o Sendero Luminoso no Peru - com o tráfico de cocaína naquilo que seria uma nova ameaça à segurança continental (LABROUSSE, 2010). Esse fenômeno foi denominado como narcoterrorismo e serviu de justificativa 


\section{Thiago Rodrigues}

adicional para que os EUA insistissem na necessidade de combater militarmente o narcotráfico e para que os governos andinos adotassem leis de exceção e medidas repressivas que resultaram no aumento generalizado da violência, sem diminuir a oferta de cocaína (RODRIGUES, 2006).

No entanto, os EUA insistiram na urgência em militarizar o combate ao narcotráfico na América Latina e Caribe. Em abril de 1986, Reagan editou uma "National Security Decision Directive" (NSDD), de número 221, intitulada "Narcotics and National Security", em que afirmava que "alguns grupos insurgentes financiam suas atividades pela taxação de ações vinculadas ao tráfico de drogas, provendo proteção a traficantes locais ou cultivando suas próprias colheitas de drogas" (NSDD-221, 1986, p. 2). O presidente "oficializava", assim, a tese das narcoguerrilhas, sustentando que

\footnotetext{
[...] a ameaça à segurança nacional colocada pelo tráfico de drogas é particularmente séria fora das fronteiras dos EUA. São fontes de preocupação aquelas nações com florescente indústria de narcóticos, onde a combinação de organizações criminosas do tráfico internacional, insurgentes rurais e terroristas urbanos pode minar a estabilidade de governos locais [de modo que a] expansão das atividades narcotraficantes [...] cria tanto um problema regional quanto específico a cada país (NSDD-221, 1986, p. 1; tradução nossa).
}

O documento assinado por Reagan retomou e ampliou, portanto, a definição dada por Nixon, na década anterior, de que o narcotráfico era uma ameaça à segurança nacional dos EUA, acrescentando seu potencial como perigo à segurança nacional de cada país do hemisfério onde houvesse atividade narcotraficante. Desse modo, o narcotráfico deixou de ser encarado apenas como um problema de segurança nacional estadunidense para ser, também, classificado como uma 


\section{Narcotráfico e Militarização nas Américas: Vício de Guerra}

questão de segurança nacional de cada país que contasse com tráfico ilícito em seu território. Assim, despontava a avaliação, por parte dos Estados Unidos, de que o narcotráfico crescera ao ponto de ser, também, um problema de segurança regional.

Para enfrentar tamanha "ameaça", a NSDD-221 recomendou um esforço continental para combater a produção, tráfico e consumo de drogas ilícitas, e anunciou a intenção dos EUA de apoiar a "guerra às drogas" já conduzidas pelos Estados latino-americanos e caribenhos. Para tanto, Reagan ordenou que o secretário de Defesa, o procurador-geral e o secretário de Estado desenvolvessem e implementassem "toda modificação necessária aos estatutos, regulamentos, procedimentos e linhas mestras em vigor a fim de habilitar as Forças Armadas estadunidenses a dar suporte mais ativo aos esforços de combate ao narcotráfico, consistentes com a manutenção de sua necessidade de preparo e treinamento" (NSDD-221, 1986, p. 3).

Essa indicação de Reagan exortava a diplomacia e o aparato militar estadunidenses a que trabalhassem juntos de modo a oferecer apoio à militarização continental da "guerra às drogas". No entanto, o tema era delicado, pois implicava na necessidade de alterar limites legais vigentes nos próprios Estados Unidos.

Em especial, a decisão de Reagan confrontava o "Posse Comitatus Act", lei federal promulgada em 1878 que estabelecia as funções das Forças Armadas, delimitando, por exemplo, o escopo de suas ações em território estadunidense para a manutenção da "lei e ordem" e colocando-as sob controle e acompanhamento do Congresso federal. Segundo Marcy (2010), a proposta de envolvimento militar na "guerra às drogas" gerou polêmica no ambiente político estadunidense, principalmente de políticos democratas e de ativistas dos direitos humanos, que viam tal diretriz como intervencionista. Até mesmo dentro das Forças Armadas, a decisão teria recebido críticas da parte de 
militares que temiam o desvirtuamento das funções tradicionais de defesa nacional.

Ao mesmo tempo, na América Latina, a disposição dos EUA de apoiar a militarização do combate ao narcotráfico gerou resistências de setores nacionalistas, de políticos de esquerda e movimentos sociais - como os cocaleros bolivianos -, mas foi encampada, em maior ou menor grau, por sucessivos governos à esquerda e à direita. Para Serrano e Toro (2005, p. 242-243), "a política antidrogas dos Estados Unidos incluía a colaboração de muitos governos latino-americanos, que receberam cada vez mais ajuda econômica e técnica, adotaram programas de capacitação da polícia dos EUA e se converteram em anfitriões de numerosos agentes da DEA"; além disso, nesses países, "destinaram-se cada vez mais policiais e soldados para as tarefas antidrogas".

A adesão dos países latino-americanos foi impulsionada por pressões diplomático-econômicas, com destaque para o processo de “certificação", pelo qual, a partir do governo Reagan, os presidentes estadunidenses passaram a publicar anualmente uma lista dos países que, na avaliação dos EUA, colaboraram ou não com a "guerra às drogas" no ano anterior, prevendo sanções econômicas e reprimendas diplomáticas aos descumpridores. Todavia, o acatamento da lógica punitiva e da militarização por Estados latino-americanos respondeu, também, a processos próprios a cada país que já eram - à época das decisões de Reagan - signatários dos tratados proibicionistas e que já procediam, cada qual a seu modo, o combate às drogas como tática de governo e repressão seletiva sobre suas próprias populações.

A militarização do combate ao narcotráfico foi reforçada no mandato de George Bush (1989-1993), que, quando vice-presidente de Reagan, foi o coordenador das políticas antidrogas estadunidenses. Bush editou, em agosto de 1989, uma "National Security Directive", de 


\section{Narcotráfico e Militarização nas Américas: Vício de Guerra}

número 18, intitulada "International Counternarcotics Strategy", em que reforçou a avaliação do narcotráfico como uma ameaça à segurança regional contida na NSDD-221, destacando a importância de focar as atenções na Colômbia, no Peru e na Bolívia, tidos como as principais fontes da cocaína consumida nos EUA.

Essa política, que seria nomeada "Estratégia Andina", mencionava a necessidade de oferecer suporte econômico para que os países da região pudessem deixar de ser "produtores", de modo a financiar programas de desenvolvimento alternativos. No entanto, o documento somente requisitou recursos para "assistência militar", o que significava "expandir o apoio do Departamento de Defesa nos esforços antidrogas dos EUA" e permitir que pessoal desse Departamento treinasse e desse apoio aos três países, com a ressalva de que "não acompanhassem as forças dos Estados andinos em operações de campo" (NSD-18, 1989, p. 3). Com isso, "todo o dinheiro direcionado à Estratégia Andina tomou a forma de assistência militar [...] com poucas restrições ao seu uso, o que significava que os recursos poderiam ser usados para combater guerrilhas de modo a garantir a eficácia das ações antidrogas" (MARCY, 2010, p. 138). A NSD-18 anunciava, ainda, um encontro com mandatários sul-americanos, que, de fato, seria organizado poucos meses depois, já no início de 1990, em Cartagena, Colômbia.

Antes disso - e apenas um mês depois da NSD-18 -, a Casa Branca publicou a "National Drug Control Strategy", extenso documento que registrou o compromisso proibicionista do governo Bush voltado, no plano exterior, à militarização do combate ao tráfico de drogas. Como um dos efeitos diretos dessa ênfase repressiva e militarizada, em dezembro de 1989, o então presidente do Panamá, Manuel Noriega, foi preso por militares estadunidenses e enviado aos EUA, onde fora condenado por "tráfico de drogas", encerrando uma longa parceria entre Noriega e os Estados Unidos no suporte aos grupos armados de direita na América Central, financiados parcialmente com 
dinheiro oriundo do narcotráfico (DALE SCOTT; MARSHALL, 1998).

Ainda sob efeito da prisão de Noriega, realizou-se a acima mencionada reunião em Cartagena, na qual Bush e os presidentes andinos discutiram a operacionalização da "guerra às drogas" para a década que se iniciaria, seguindo as premissas estadunidenses. Uma das propostas dos EUA foi a criação de uma força militar multinacional coordenada por oficiais estadunidenses. Diante da resistência dos presidentes e de grupos políticos nos EUA e na América Latina, a proposta não vingou nesse formato. Uma decisão nesse sentido ficou adiada para novo encontro, que aconteceu em 1992, em San Antonio, Texas. Nessa ocasião, não se voltou a falar de força multilateral, mas de reafirmação do compromisso com o combate e repressão ao narcotráfico. Esse compromisso geral recebeu o nome, em 1994, durante a primeira Cúpula das Américas, realizada em Miami, de "princípio da responsabilidade compartilhada", por meio do qual os países endossavam que o narcotráfico era uma ameaça para todos, e que necessitava ser enfrentada coletivamente a partir da lógica da "guerra às drogas".

Esse princípio, defendido pela diplomacia do governo Bill Clinton (1993-2001), espelhou as decisões tomadas na já mencionada Conferência de Viena sobre Drogas, de 1988, que havia acrescentado novos temas ao "perigo das drogas", como a lavagem de dinheiro e o vínculo com outras atividades do chamado crime organizado transnacional (como o tráfico de armas e de pessoas), mas reforçou a tônica do combate policial e militar aos usuários e traficantes de drogas. Desse modo, o documento final da Conferência de Viena registrou, ainda, que o narcotráfico deveria ser considerado uma ameaça à ordem internacional, fato que fez com que se acrescesse, em adição aos planos da segurança nacional e regional, o do narcotráfico como problema de segurança global (HERSCHINGER, 2011; RODRIGUES, 2006). 


\section{Narcotráfico e Militarização nas Américas: Vício de Guerra}

Clinton ainda reavivou a prática das certificações, brandindo a possibilidade de utilizar a descertificação como um instrumento eficaz de pressão e alinhamento estratégico. Em documentos como a "Presidential Decision Directive" n. 42, intitulada "International Organized Crime", de 1995, destacou o crime organizado como ameaça à segurança dos EUA e internacional, com destaque para o poder econômico e de abalo político-institucional do narcotráfico (PDD-42, 1995; INKSTER; COMOLLI, 2012). No entanto, como mencionado anteriormente, apesar da pressão diplomático-militar estadunidense, a ampla aceitação da "guerra às drogas" pelos países latino-americanos não foi apenas efeito de coação. Cada Estado teve um modo particular de incorporar o modelo proibicionista que respondia a dinâmicas internas. Nos países andinos, o vínculo apontado entre narcotráfico e guerrilhas de esquerda permitiu que a adesão à "guerra às drogas" fornecesse meios materiais, apoio diplomático e justificativas morais para travar suas guerras internas.

Em outros Estados, como no Brasil e no México, a "guerra às drogas" reforçou políticas de segurança pública voltadas à repressão seletiva aos grupos sociais empobrecidos (BATISTA, 2003). Em suma, a adesão por parte dos países latino-americanos não foi uma mera sujeição à agenda de segurança hemisférica estadunidense. Ao contrário, as intenções dos EUA encontraram pontos de conexão em cada país que aderiu ao proibicionismo. Os Estados latino-americanos não foram, assim, meras marionetes dos interesses geopolíticos estadunidenses traduzidos nas ações da "guerra às drogas". Por isso, alguns deles, como a Colômbia, o México e o Brasil podem ser interessantes laboratórios de análise desse processo de adequação local ao proibicionismo militarista financiado pelos Estados Unidos.

\section{A Recorrência da Guerra}

O caso colombiano explicita a dupla situação na qual a "guerra às drogas" envolve interesses estadunidenses e objetivos políticos lo- 


\section{Thiago Rodrigues}

cais. O atual conflito interno no país data dos anos 1960, com procedências remontando pelo menos ao final dos anos 1940, envolvendo guerrilhas de esquerda, o Estado e, posteriormente, grupos paramilitares de direita (PÉCAUT, 2010). O aparecimento dos grupos narcotraficantes no final dos anos 1970 tornou ainda mais conturbado o panorama dos múltiplos enfrentamentos armados no país. Para os governos da Colômbia e dos EUA, desde as declarações de Reagan nos anos 1980, guerrilheiros e paramilitares estão envolvidos, em algum grau, com o narcotráfico internacional. Com isso, o problema do conflito civil colombiano coligaria o tráfico de drogas às principais ameaças ao Estado, configurando um caso de segurança nacional (DUARTE VILLA; OSTOS, 2007). Nesse ponto, nota-se a convergência de interesses, nos discursos diplomático-militares dos EUA e da Colômbia, da definição do narcotráfico como um problema de segurança nacional.

Assim, não foi em um contexto sem procedências que o presidente Andrés Pastrana anunciou, em 1999, a existência de negociações de seu país com os EUA para a elaboração de um amplo pacote de ajuda destinado a combater o narcotráfico. Não obstante, a abrangência e o valor do financiamento - em torno de US\$ 7 bilhões - foram inéditos no histórico dos programas militares dos Estados Unidos nas Américas. Em princípio, o Plano Colômbia, como foi nomeado o pacote de ajuda militar iniciado em 2000, liberava financiamento para as ações antidrogas, mas não especificamente para o combate às guerrilhas, notadamente, as FARC. Todavia, após os ataques terroristas de setembro de 2001, e da declaração de guerra ao terror pelos EUA, as restrições para o emprego da força terminaram, pois tanto as FARC quanto o Exército de Libertação Nacional (ELN) e os paramilitares, classificados todos como grupos terroristas, teriam seu combate justificado pela acoplagem realizada então entre a war on terror e a war on drugs (LABROUSSE, 2005). 


\section{Narcotráfico e Militarização nas Américas: Vício de Guerra}

Desse modo, a partir de 2001, as guerrilhas passaram a ser alvo de ataques massivos do Estado colombiano - notadamente as FARC -, sofrendo sérias derrotas que incluíram a libertação de notórios reféns - como a ex-senardora Ingrid Betancourt, em 2008 - e o assassinato de líderes, como Raúl Reyes, também em 2008, tido como segundo na hierarquia de comando das FARC. Fragilizadas, em uma situação muito diferente de uma década atrás, quando contavam com uma zona desmilitarizada na qual puderam abrigar-se com segurança, as FARC retrocederam, no final dos anos 2000, a níveis de organização e operacionalidade precários (TORRES DEL RÍO, 2010; SANTANA, 2004). Portanto, seria possível dizer que a adesão colombiana à agenda de segurança dos EUA - sobre drogas e terrorismo - conectou sua guerra civil às guerras globais às drogas e ao terrorismo mantidas pelos estadunidenses, fortalecendo a presença e o poder soberano do Estado colombiano sobre seu território e população (SANTOS, 2011).

O Plano Colômbia não teve, todavia, a capacidade de abalar significativamente o narcotráfico no país. Dados da ONU, que podem ser considerados conservadores, pois informados pelos Estados-membros, indicam que a diminuição da área cultivada com arbustos de coca na Colômbia não implicou em um decréscimo significativo do fabrico de cocaína - o que sugere uma maior eficiência na produção -, assim como não alterou a diversificação produtiva, com a persistência da cultura de papoula voltada à produção de heroína, introduzida no país, em maior escala, a partir dos anos 1990 (UNITED NATIONS OFFICE ON DRUGS AND CRIME, 2012).

O plano não enfraqueceu o narcotráfico no país, mas estimulou a pulverização ainda maior dos grupos, processo que já ocorria desde o desmantelamento dos chamados "Cartéis" de Medellín e de Cali, na primeira metade dos anos 1990. Essa situação teria debilitado parcialmente a capacidade dessas empresas ilícitas colombianas de se conectar aos canais de distribuição atacadista internacional - principal- 
mente os relacionados ao mercado estadunidense -, o que fortaleceu narcotraficantes de outros países, em especial os mexicanos (RODRÍGUEZ LUNA, 2010).

Assim, há autores que associam, em parte, o crescimento dos grupos narcotraficantes mexicanos nos anos 2000 ao enfraquecimento relativo das empresas do tráfico de drogas colombianas a partir dos efeitos do Plano Colômbia e da política de segurança dos mandatos de Álvaro Uribe (2002-2010): “o combate frontal à oferta de drogas controlada pelos cartéis colombianos, [provocou] alteração das rotas do narcotráfico, passando [das que atravessavam] pelo Caribe, utilizadas pelos colombianos, para as do Golfo do México, do Pacífico e da América Central e, claro, pelo próprio território mexicano" (RODRÍGUEZ LUNA, 2010, p. 40), acentuando o poder dos grupos baseados no México.

O agravamento da situação mexicana, no entanto, levou o governo de Felipe Calderón (2006-2012) a optar pela mesma diretriz da política colombiana, seguida e aplicada há mais de vinte anos: endurecer e militarizar o combate ao narcotráfico (RAVELO, 2011). A opção de Calderón pelo enfrentamento militarizado ao narcotráfico foi, parcialmente, uma tática para angariar apoio popular após uma vitória eleitoral contestada pela oposição, fazendo uso da grande sensibilidade da sociedade mexicana ao tema da violência entre os grupos ou "cartéis" mexicanos e, em parte, uma continuação de práticas históricas de repressão interna a movimentos sociais e contestações à ordem política e econômica conduzidas pelo Estado central por meio das Forças Armadas (BOYER, 2012). O “quadro de violência” gerado pela disputa entre as empresas narcotraficantes teria, no entanto, servido como catalisador para justificar um aumento do poder central sobre as unidades federais no México, além de endurecer as políticas repressivas no país (BENÍTEZ MANAUT, 2010).

No entanto, a decisão de envolver militares no combate ao tráfico de drogas no México não foi uma inovação de Calderón, remontando à 


\section{Narcotráfico e Militarização nas Américas: Vício de Guerra}

própria emergência da “guerra às drogas" nos anos 1970, com repercussões imediatas no México (RODRIGUES, 2004). Seu ineditismo estaria na ênfase dada às Forças Armadas - Exército e Marinha, em particular - como responsáveis por enfrentar organizações como os "cartéis" de Sinaloa, La Familia Michoacana, o de Tijuana, o do Golfo ou o de Juárez. O suporte financeiro e político veio logo em seguida à sua posse, quando Calderón e George W. Bush celebraram, em 2007, um acordo que instituiu a Iniciativa Mérida, plano de apoio financeiro, de treinamento militar, de compra de equipamento bélico e para a reforma do aparato judiciário voltado para combater o narcotráfico, e que previu a liberação em sua primeira fase - no biênio 2007/2009 - de US\$ 1,3 bilhão. Os principais beneficiários foram a Secretaria de Defesa Nacional (SEDENA), equivalente ao Ministério da Defesa no Brasil e à Secretaria de Defesa nos EUA, e a Secretaria de Marinha Armada (SEMAR), com recursos voltados à compra de armamentos, veículos militares, dispositivos eletrônicos de rastreamento e treinamento de pessoal (RODRÍGUEZ LUNA, 2010).

Os resultados mais concretos da "guerra às drogas" de Calderón foram cerca de 50 mil mortos gerados pelos embates entre grupos narcotraficantes e deles com as forças de segurança do Estado (RAVELO, 2011). Essa quantidade expressiva de mortos, no entanto, não foi acompanhada da desmobilização das empresas narcotraficantes mexicanas. Esses fatos não impediram que o programa fosse mantido em uma segunda fase, já com Barack Obama na Presidência estadunidense. A vitória de Enrique Peña Nieto (Partido Revolucionário Institucional [PRI]) para a Presidência do México, em julho de 2012, após campanha eleitoral na qual os principais candidatos não ofereceram alternativas à política de enfrentamento colocada em marcha por Calderón - associada ao início da Iniciativa Mérida II -, indica uma tendência de continuidade no processo de militarização do combate ao narcotráfico no país. 
Por outro lado, o caso brasileiro foi, até hoje, distinto dos casos colombiano e mexicano. Considerado nos anos 1980 um "corredor de exportação de cocaína" (LABROUSSE; DELPIROU, 1988), o Brasil é tido hoje como um país consumidor e produtor de drogas ilícitas, além de importante praça para a lavagem de dinheiro (FARRER, 2003; GLENNY, 2008). Como nos demais países americanos, o tráfico de drogas é, no Brasil, associado a populações pobres, habitantes de favelas e periferias e vinculado aos chamados comandos ou partidos do crime. Apesar de a situação da produção, tráfico e consumo de drogas ilícitas no Brasil não configurar um quadro tão simples, o vínculo entre narcotráfico e pobreza tem justificado seguidos programas de segurança pública que insistem na repressão e no proibicionismo como meios para lidar com a questão das drogas.

A atual reformulação do aparato antidrogas brasileiro foi iniciada no governo Fernando Henrique Cardoso (1995-2002) com a criação, em 1996, da Secretaria Nacional Antidrogas (SENAD), vinculada à Casa Militar da Presidência da República, prevendo que ela atuaria como Secretaria Executiva do Conselho Nacional Antidrogas (Medida Provisória 1669). O art. $6^{\underline{0}} \S 1^{\circ}$ dessa medida provisória atribuía competência à Casa Militar para "coordenar e integrar as ações do Governo nos aspectos relacionados com as atividades de prevenção e repressão ao tráfico ilícito, ao uso indevido e à produção não autorizada de substâncias entorpecentes e drogas que causem dependência, bem como aquelas relacionas com a recuperação de dependentes". Mesmo após a reforma de 1998, que rebatizou a Casa Militar como Gabinete de Segurança Institucional (GSI), a SENAD seguiu a ele vinculado, tendo como secretário o general Paulo Roberto Uchôa.

O projeto de produzir uma secretaria que centralizasse a aplicação da política de drogas no Brasil, produzindo uma versão nacional da DEA estadunidense, esbarrou em uma questão constitucional, uma vez que a Carta de 1988 estabelece que as atribuições que a Medida Provisória 1669 pretendia vincular à SENAD eram de competência 


\section{Narcotráfico e Militarização nas Américas: Vício de Guerra}

da Polícia Federal (Constituição Federal, art. 144). Assim, a SENAD foi esvaziada, tornando-se um órgão para a articulação das políticas de prevenção, educação e pesquisa sobre as drogas ilícitas no país. Apesar do seu enfraquecimento, é importante destacar que a SENAD se originou associada à Casa Militar e com um militar à frente de uma secretaria destinada a pensar políticas para a prevenção do uso de drogas. Já no governo Lula, após a reforma na Lei de Tóxicos de 1976, que gerou a atual Lei 11.343, de 2006, a SENAD mudou de nome para Secretaria Nacional de Políticas sobre Drogas, permanecendo com as mesmas funções. Seu comando permaneceu com o general Uchôa durante os dois mandatos de Lula da Silva (2003-2010), sendo transmitido a um secretário civil - que tem status de ministro apenas no início do governo Dilma Rousseff, em 2011. ${ }^{1}$

Antes disso, ainda no governo Cardoso, foi desenvolvido o Sistema de Vigilância Amazônico (SIVAM), voltado ao controle do espaço aéreo, solo e subsolo da Amazônia brasileira por meio de radares fixos, satélites e aviões-radares, que faz parte do Sistema de Proteção Amazônico (SIPAM) e integra o programa geral de monitoramento do espaço aéreo do país pela Força Aérea. O projeto SIPAM/SIVAM é um desdobramento dos programas de proteção do espaço amazônico, desenvolvidos durante a ditadura civil-militar (1964-1985), que visa "produzir informação, especialmente sobre biodiversidade e atividades ilegais; gerar uma ação governamental estratégica e integrada; estimular o desenvolvimento e reforçar a soberania [sobre a região]" (HERZ, 2006, p. 207). As polêmicas em torno da formação do SIVAM, nos anos 1990, envolveram denúncias de favorecimento de empresas estrangeiras na licitação do projeto, bem como questões referentes à responsabilidade sobre o gerenciamento dos dados fornecidos pelo sistema. A solução foi deixá-lo a cargo da Força Aérea, seguindo a política de controle militar do espaço aéreo brasileiro (BRIGAGÃO, 1996). O fato é que o SIVAM aumentou expressivamente a capacidade do Estado brasileiro em monitorar e controlar 


\section{Thiago Rodrigues}

não só o espaço aéreo, mas também a superfície e o subsolo amazônicos, em um aumento de poder soberano sobre a região. Nos anos de Cardoso na Presidência, já havia pressão estadunidense para um maior envolvimento das Forças Armadas no combate ao narcotráfico, ultrapassando as atividades de apoio logístico realizadas até então (PROCÓPIO; VAZ, 1997).

No campo jurídico, o debate para uma revisão da Lei de Tóxicos, editada durante a ditadura, em 1976, resultou, no mando de Fernando Henrique Cardoso, em tópicas alterações que não alteraram sua tônica repressiva. A efetiva promulgação de outra lei sobre drogas - a mencionada Lei 11.343 - aconteceu já no governo de Lula da Silva, e introduziu o tema das penas alternativas para consumidores, mantendo a distinção entre "usuários" e "traficantes" existente na lei estabelecida no regime militar, sem especificar quantidades claras que tipificariam "posse para uso pessoal" ou "tráfico de drogas". Resultado imediato dessa imprecisão foi a permanência da seletividade penal na captura de indivíduos segundo sua procedência social, cor de pele e outros estereótipos que seguiram determinando, na prática punitiva, a "categoria" de enquadramento penal. ${ }^{2}$

A reforma penal sobre drogas, no entanto, manteve o princípio de que o tráfico internacional de drogas deveria ser combatido pela Polícia Federal, enquanto a investigação policial permaneceria nos departamentos especializados das Polícias Civis estaduais, e a repressão imediata seguiria com o patrulhamento ostensivo das Polícias Militares. Nessa lei, portanto, não havia a determinação de que as Forças Armadas devessem participar do combate ao narcotráfico. Não obstante, desde o final dos anos 1990, algumas decisões do governo federal aumentaram a participação dos militares na repressão às chamadas atividades ilícitas transnacionais. O decreto presidencial $\mathrm{n}^{\mathrm{o}}$ 5.144/2004, conhecido como "Lei do Abate", regulamentou que aeronaves que não obedecessem à ordem de se identificar quando solicitadas pelo controle do espaço aéreo brasileiro poderiam ser, no li- 


\section{Narcotráfico e Militarização nas Américas: Vício de Guerra}

mite e após autorização presidencial, abatidas pela Força Aérea, em uma tentativa de coibir os voos clandestinos associados ao narcotráfico e outros ilícitos transnacionais, como o tráfico de armas.

Maior repercussão, todavia, teve a regulamentação da Lei Complementar 97, realizada em 2010, e que deu poder de polícia - patrulhamento, revista de veículos e pessoas e prisões em flagrante - para as Forças Armadas na faixa de fronteira, nas águas interiores e no mar territorial brasileiro (art. 16A da Lei Complementar 97/1999 alterada pela Lei Complementar 136/2010). Com isso, além da Polícia Federal, as fronteiras do país poderiam ser patrulhadas pelas Forças Armadas, adicionando atribuições antes restritas à tradicional proteção dos limites nacionais diante de ataques de Forças Armadas estrangeiras, sem autorização para abordagem e revista. A mesma lei complementar, no seu art. 15, também estabeleceu regras para o emprego das Forças Armadas na "manutenção da lei e ordem", prerrogativa constitucional que não havia ainda sido regulamentada ou especificada desde 1988.

Entre as disposições, está a de que, após autorização presidencial para o emprego das Forças Armadas, o comando das operações de segurança pública ficaria a cargo de uma autoridade militar em ações necessariamente temporárias e circunscritas territorialmente. É importante notar que a assinatura dessa lei complementar pelo presidente Lula aconteceu em agosto de 2010, cerca de três meses antes das operações levadas a cabo no Complexo de Favelas do Alemão, no Rio de Janeiro, quando foi aplicada pela primeira vez.

Essa operação, iniciada após uma série de ataques a veículos de transporte público e autoridades policiais, em outubro de 2010, supostamente a cargo de traficantes que atuavam no Complexo do Alemão, levou à articulação de uma ação integrada de grandes proporções entre forças policiais civis e militares, Polícia Federal, Polícia Rodoviária Federal e Forças Armadas (principalmente os Fuzileiros 
Navais e o Exército), que invadiram as favelas para a execução da chamada Operação Arcanjo: consolidar a ocupação do Estado no Complexo, de modo a permitir a entrada de Unidades de Polícia Pacificadora (UPPs), programa de segurança pública do governo do estado do Rio de Janeiro que visa a reconquista territorial de favelas, com a instalação de postos permanentes da polícia militar, orientados por critérios de policiamento comunitário, de modo a permitir a entrada de serviços públicos e privados nessas comunidades e a expulsão dos traficantes. Projeto caracterizado por discurso "militar" - lidando com expressões como conquista territorial, ocupação estratégica, pacificação -, as UPPs começaram a ser instaladas no Complexo do Alemão em maio de 2012, marcando a transição gradual de policiamento da Força de Pacificação militar para a Polícia Militar, consolidado no início de julho de 2012.

Essa não foi, entretanto, a primeira vez que as Forças Armadas atuaram no campo da segurança pública no Rio de Janeiro, visando a contenção ou vigilância sobre favelas e seus moradores. Houve antecedentes importantes, como a operação de segurança durante a realização da Cúpula da Terra da ONU, em 1992, ou a visita do papa João Paulo II, em 1998. Tampouco foi a primeira vez em que a sociedade aplaudiu essa forma de atuação. No entanto, a utilização de militares na segurança pública no Brasil é tema polêmico que suscita questões conceituais e políticas (ZAVERUCHA, 2008; ARRUDA, 2007). Do ponto de vista conceitual, desafia-se a divisão tradicional entre segurança pública e segurança nacional, pois as Forças Armadas são compreendidas, no modelo republicano de procedência ocidental, como o braço armado do Estado para sua defesa diante de ataques externos (FIGUEIREDO, 2010), que seriam, principalmente, agressões promovidas por forças regulares de outros Estados, ou, quando no ambiente doméstico, por forças irregulares (guerrilhas) reconhecidas como forças beligerantes (ANAND, 2009). 


\section{Narcotráfico e Militarização nas Américas: Vício de Guerra}

O narcotráfico, ao contrário, é composto por fluxos que atravessam fronteiras e, ainda que provenha do exterior, não é composto por forças estatais ou paraestatais, mas por grupos privados atuando em um negócio transterritorial, sem objetivos políticos tradicionais. São empresas ilícitas transterritoriais, pois têm, simultaneamente, bases e atuação locais (produção e comercialização) e trânsito transnacional, ultrapassando fronteiras políticas para sua realização como negócio.

No entanto, como analisado acima, o narcotráfico foi construído desde o princípio como um problema nacional e internacional. Sua produção como uma questão de saúde pública e segurança pública foi concomitante à construção de um regime internacional de controle de drogas pautado na mesma lógica proibicionista que orientava, desde o início do século XX, as reformas jurídicas domésticas, acionando táticas de repressão internas. Nos anos 1970, quando o discurso estadunidense incorporou o plano da segurança nacional, rapidamente essa tônica foi adotada em todo o planeta, levando, na década de 1980, à definição do tráfico de drogas como um tema de segurança global.

A análise da "guerra às drogas" e do narcotráfico como temas de segurança global coloca-os no campo de estudo dos "novos conflitos internacionais" ou das "novas ameaças" (KALDOR, 2006; KAN, 2009) ou, mais precisamente, daquilo que Frédéric Gros (2009) chamou de "estados de violência": conflitos continuados ou descontinuados, de irrupção surpreendente e muitas vezes efêmeros, conduzidos por grupos privados transterritoriais (terroristas, narcotraficantes, traficantes de pessoas, armas etc.) que mobilizam a repressão de forças estatais (militares, polícias, coalizões) e que abalam a espacialidade clássica das guerras, sua temporalidade definida, sua distinção entre combatentes e não combatentes e sua regulamentação tradicional (com tratados e tribunais ad hoc ou o permanente Tribunal Penal Internacional). 
Assim, seria possível dizer que o amplo processo de securitização planetária do narcotráfico confunde ou interseciona os espaços de segurança doméstico e internacional. Essa sobreposição de planos de segurança propicia que discursos diplomático-militares proibicionistas, com os Estados Unidos à frente, justifiquem a utilização das Forças Armadas no enfrentamento ao narcotráfico, pois, simultaneamente, a soberania e a ordem interna dos Estados estariam ameaçadas.

O catastrofismo dessa avaliação tem repercussões mais diretas, no entanto, em sociedades, como as latino-americanas, em que as Forças Armadas tiveram, historicamente, um papel de pacificação de revoltas e de conquista interna, além de inúmeras intervenções na vida política desses países, redundando em regimes autoritários. Desde os processos de independência nacional no século XIX, os militares latino-americanos foram frequentemente acionados para enfrentar inimigos internos, fossem populações autóctones, subversivos urbanos ou rurais, guerrilheiros ou sublevados. Foram poucas as guerras interestatais entre latino-americanos desde então; e menor ainda o engajamento de suas Forças Armadas em guerras interestatais extracontinentais.

O uso de Forças Armadas contra próprios concidadãos parece ter sido, então, uma constante na história latino-americana, e a adoção entre nós da militarização do combate ao narcotráfico talvez possa ser compreendida como um redimensionamento contemporâneo desse processo, especialmente quando se nota que tal política permanece voltada à repressão seletiva de grupos sociais historicamente visados pelas táticas de controle social. Eis uma hipótese que exige pesquisa de maior fôlego e à qual começa, agora, a se dedicar esse pesquisador.

No entanto, é possível afirmar a importância de se conhecer a história política do regime internacional de drogas e da ênfase repressiva que, 


\section{Narcotráfico e Militarização nas Américas: Vício de Guerra}

em termos geopolíticos e no plano global, foram traduzidos no apoio à militarização do combate ao narcotráfico. Em tempos em que se completa cem anos das iniciativas internacionais proibicionistas que emergiram de procedências domésticas que associavam práticas moralistas, discursos médico-sanitaristas e táticas de governo das populações, tal compreensão possibilita uma análise mais contundente dos programas de segurança pública na América Latina - dos mais e dos menos alternativos ou progressistas - e dos rumos das Forças Armadas no continente.

Mais do que isso, é preciso saber essa história para problematizar não apenas o proibicionismo, como também os discursos reformistas que, mesmo críticos à criminalização das drogas, limitam-se, muitas vezes, a apontar o fracasso do proibicionismo militarista no que diz respeito aos seus objetivos de erradicar hábitos e práticas relacionados a algumas substâncias psicoativas, sugerindo novas medidas legais globais que não prescindem da punição e da seletividade, ainda que traduzidas em discursos humanitaristas e de saúde pública. Criticar o proibicionismo por seus efeitos não é exercício demasiado difícil, bastando acompanhar o agravamento ininterrupto das situações de violência, de prejuízo à saúde e de potencialização de conflitos ensejadas, nesse último século, pelo regime internacional de controle de drogas. Mais interessante, porém, pode ser a busca por compreender a recorrência e a reafirmação do proibicionismo centrado na repressão e na militarização presente - apesar do seu constado "fracasso" - em cada tratado internacional, cúpula de chefes de Estado, plano de ajuda econômica ou reforma jurídica doméstica.

Do ponto de vista analítico, o estudo da militarização do combate ao narcotráfico tem a potência de explicitar os estados de violência cotidianos acionados pelo proibicionismo, dentro e fora das fronteiras, e que faz da fórmula "guerra às drogas" um combate efetivo e continuado. Com isso, explicitam-se problemas cruciais das contemporâneas questões de segurança, que colocam tanto desafios conceituais - 


\section{Thiago Rodrigues}

para os referenciais clássicos das Relações Internacionais e dos estudos estratégicos sobre conflitos, soberania e guerra - quanto problemas políticos que, para serem enfrentados, não se pode ignorar o tanto de moralismo e de punição seletiva que lastreia interesses econômicos e geopolíticos relacionados a esse secular "fracasso", sempre reeditado e redimensionado, com seus milhares de mortos e múltiplas violências.

\section{Notas}

1. No início do mandato de Dilma Rousseff, em janeiro de 2011 , foi cogitado o nome do advogado Pedro Abramovay para assumir a Secretaria Nacional Antidrogas (SENAD). Abramovay havia sido secretário nacional de Justiça no final do segundo mandato de Lula da Silva e tinha histórico de envolvimento no debate sobre drogas no país. No entanto, após entrevista dada por Abramovay ao jornal $\mathbf{O}$ Globo, no dia 11 de janeiro de 2011, em que defendeu o fim da prisão para pequenos traficantes, seu nome foi vetado pela presidente e pelo então novo ministro da Justiça, José Eduardo Cardozo.

2. Na ausência de especificação sobre a quantidade de drogas ilícitas que diferenciariam "uso pessoal" de "tráfico", a Lei de 2006 deixou a cargo da autoridade policial (delegado de polícia) a responsabilidade de definir se uma pessoa flagrada com psicoativos ilegais seria "usuário" ou "traficante". Isso, na prática, oficializou a seletividade penal já em prática, que termina por encarcerar pobres, negros e favelados, eximindo de processo penal (pelo encaminhamento para penas alternativas ou, simplesmente, pelo não registro de ocorrência após suborno ou extorsão) pessoas procedentes de grupos sociais economicamente mais abastados. 


\section{Referências Bibliográficas}

ANAND, Ruchi. Self-defense in International Relations. Nova Iorque: Palgrave Macmillan, 2009.

ARRUDA, João Rodrigues. O uso político das Forças Armadas e outras questões militares. Rio de Janeiro: Mauad X, 2007.

BATISTA, Vera Malaguti. Difíceis ganhos fáceis: drogas e juventude pobre no Rio de Janeiro. Rio de Janeiro: Instituto Carioca de Criminologia, 2003.

BENÍTEZ MANAUT, Raúl. México 2010: crimen organizado, seguridad nacional y geopolítica. In: BENÍTEZ MANAUT, R. (Ed.). Crimen organizado e Iniciativa Mérida en las relaciones México-Estados Unidos. Cidade do México: CASEDE, 2010. p. 9-30.

BOYER, Jean-François. No México, o Estado recua diante dos cartéis. Le Monde Diplomatique Brasil, n. 60, p. 18-20, jul. 2012.

BRIGAGÃO, Clóvis. Inteligência e marketing: o caso SIVAM. Rio de Janeiro: Record, 1996.

BUZAN, Barry; W ÆVER, Ole; DE WILDE, Jaap. Security: a new framework or analysis. Boulder: Rienner, 1998.

DALE SCOTT, Peter; MARSHALL, Jonathan. Cocaine politics: drugs, armies and the CIA in Central America. Berkeley: University of California Press, 1998.

DUARTE VILLA, Rafael; OSTOS, María de Pilar. Colômbia: evolução de sua política externa em relação aos EUA e seus vizinhos In: DUARTE VILLA, R.; KALIL, S. (Org.). Ensaios latino-americanos de política internacional. São Paulo: Editora Hucitec, 2007. p. 197-236.

FARRER, Tom. Transnational crime in the Americas. Nova Iorque: Routledge, 2003.

FIDLER, David P. The globalization of public health: the first 100 years of international health diplomacy. Bulletin of the World Health Organization, v. 79, 2001. 


\section{Thiago Rodrigues}

FIGUEIREDO, Eurico de Lima. Os estudos estratégicos, a defesa nacional e a segurança internacional. In: MARTINS, C. B.; LESSA, R. (Coord.). Horizontes das ciências sociais no Brasil: ciência política. São Paulo: ANPOCS, 2010.

FIORE, Maurício. O lugar do Estado na questão das drogas: o paradigma proibicionista e as alternativas. Novos Estudos Cebrap, n. 92, p. 9-21, mar. 2012.

FOUCAULT, Michel. O nascimento da medicina social. In: . Microfísica do poder. Trad. de Roberto Machado. Rio de Janeiro: Graal, 1998. p. 79-111.

A “governamentalidade”. In: MOTTA, M. B. da. Ditos \& Escritos. v. IV. Trad. de Manoel Barros da Motta. Rio de Janeiro: Forense Universitária, 2003. p. 281-305.

Segurança, território, população. Trad. de Eduardo Brandão. São Paulo: Martins Fontes, 2008.

GLENNY, Misha. McMÁFIA: crime sem fronteira. Trad. de Lucia Boldrini. São Paulo: Companhia das Letras, 2008.

GROS, Frédéric. Estado de violência: ensaio sobre o fim da guerra. Trad. de José Augusto da Silva. Aparecida: Ideias \& Letras, 2009.

HARGRAVES, Clare. Snow fields: the war on cocaine in the Andes. Nova Iorque: Holmes \& Meier, 1992.

HERSCHINGER, Eva. Constructing global enemies: hegemony and identity in international discourses on terrorism and drug prohibition. Nova Iorque: Routledge, 2011.

HERZ, Monica. Brazil, Andean security, and U.S. regional security policy. In: LOVEMAN, B. (Ed.). Addicted to failure. Plymouth: Rowman \& Littlefield, 2006. p. 197-223.

INKSTER, Nigel; COMOLLI, Virginia. Drugs, insecurity and failed states: the problems of prohibition. Londres: International Institute for Strategic Studies, 2012.

KALDOR, Mary. New and old wars: organized violence in a global era. Stanford: Stanford University Press, 2006.

KAN, Paul Rexton. Drugs and contemporary warfare. Washington: Potomac, 2009. 


\section{Narcotráfico e Militarização nas Américas: Vício de Guerra}

KOPP, Pierre. Économie de la drogue. Paris: La Découverte, 2006.

LABROUSSE, Alain. Drogue et terrorisme. In: MICHEL, Q. Terrorisme: regards croisés/Terrorism: cross analysis. Bruxelas: Presses Interuniversitaires Européennes, 2005. p. 47-69. no, 2010.

Geopolítica das drogas. Trad. de Monica Seincman. São Paulo: Desati; DELPIROU, Alain. Coca Coke. São Paulo: Brasiliense, 1988.

MARCY, William L. The politics of cocaine: how the U.S. foreign policy has created a thriving drug industry in Central and South America. Chicago: Lawrence Hill Books, Kindle Edition, 2010.

MCALLISTER, William. Drug diplomacy in the twentieth century. Nova Iorque: Routledge, 2000.

NSD-18. International counternarcotics strategy. Washington: The White House, 21 ago. 1989. Disponível em: <http://www.fas.org/irp/offdocs/nsd/ nsd18.pdf>. Acesso em: 16 abr. 2012.

NSDD-221. Narcotics and national security. Washington: The White House, 8 abr. 1986. Disponível em: <http://www.fas.org/irp/offdocs/nsdd/ nsdd-221.htm>. Acesso em: 14 abr. 2012.

PASSETTI, Edson. Das “fumeries” ao narcotráfico. São Paulo: Educ, 1991.

PDD-42. International organized crime. Washington: The White House, 21 out. 1995. Disponível em: <http://www.fas.org/irp/offdocs/pdd42.htm>. Acesso em: 16 abr. 2012.

PÉCAUT, Daniel. As FARC: uma guerrilha sem fins? Trad. de Ivone C. Benedetti. São Paulo: Paz e Terra, 2010.

PROCÓPIO FILHO, Argemiro; VAZ, Alcides Costa. O Brasil no contexto do narcotráfico internacional. Revista Brasileira de Política Internacional, v. 40, p. 75-122, 1997.

PROVINE, Doris Marie. Unequal under law: race in the war on drugs. Chicago: University of Chicago Press, 2007.

RAVELO, Ricardo. El narco en México: historia e historias de una guerra. México: Grijaldo, 2011. 
RIBEIRO, Ana Maria Motta. Sociologia do narcotráfico na América Latina e a questão camponesa In: RIBEIRO, A. M. M.; IULIANELLI, J. A. S. (Org.). Narcotráfico e violência no campo. Rio de Janeiro: DP\&A, 2000. p. 23-59.

RODRIGUES, Thiago. Narcotráfico, uma guerra na guerra. São Paulo: Desatino, 2003.

Política e drogas nas Américas. São Paulo: Educ, 2004.

Narcoterror e o warfare state. In: PASSETTI, E.; OLIVEIRA, S. (Org.). Terrorismos. São Paulo: Educ, 2006. p. 149-161.

RODRÍGUEZ LUNA, Armando. La Iniciativa Mérida y la guerra contra las drogas: pasado y presente. In: BENÍTEZ MANAUT, R. (Ed.). Crimen organizado e Iniciativa Mérida en las relaciones México-Estados Unidos. Cidade do México: CASEDE, 2010. p. 31-68.

SANTANA, Adalberto. El narcotráfico en América Latina. Cidade do México: Siglo Veintiuno Editores, 2004.

SANTOS, Marcelo. O conflito colombiano e o Plano Colômbia. Boa Vista: Editora UFRR, 2011.

SERRANO, Mónica; TORO, María Celia. Del narcotráfico al crimen transnacional organizado en América Latina. In: BERDAL, M.; SERRANO, M. (Org.). Crimen transnacional organizado y seguridad internacional: cambio y continuidad. Cidade do México: Fondo de Cultura Económica, 2005. p. 233-273.

TORRES DEL RÍO, César. Colombia, siglo XX: desde la Guerra de los Mil Días hasta la elección de Álvaro Uribe. Bogotá: Grupo Editorial Norma, 2010.

UNITED NATIONS OFFICE ON DRUGS AND CRIME. World drug report 2012. Viena: UNODC, 2012.

ZAVERUCHA, Jorge. La militarización de la seguridad pública en Brasil. Nueva Sociedad, n. 213, p. 128-146, jan.-fev. 2008. 


\title{
Narcotráfico e Militarização nas Américas: Vício de Guerra
}

\section{Resumo}

\section{Narcotráfico e Militarização nas Américas: Vício de Guerra}

\begin{abstract}
Nas primeiras décadas do século XX, foi construído um regime legal internacional voltado ao controle de drogas consideradas perigosas tanto à saúde individual e pública, quanto à ordem moral e social. Nos anos 1970, os Estados Unidos declararam uma "guerra às drogas" quando passaram a considerar o narcotráfico como uma ameaça à sua soberania nacional. A política sobre drogas, desde então, reforçou as medidas repressivas nos EUA e manteve o apoio ao envolvimento de militares latino-americanos no combate ao tráfico de drogas. Apesar do aumento da produção e consumo de drogas, a abordagem militarizada tem sido mantida e reatualizada, gerando um considerável cenário de violência e de conflito transterritoriais. O artigo visa apresentar uma concisa história política da militarização do combate ao narcotráfico, destacando seus efeitos na Colômbia, México e Brasil.
\end{abstract}

Palavras-chave: Narcotráfico - "Guerra às Drogas" - América Latina Estados Unidos

\section{Abstract}

\section{Drug-trafficking and Militarization in the Americas: The Addiction to War}

In the first decades of the 20th century an international legal regime was established in order to control a category of drugs seen as dangerous for individual and public health as well for the moral and social orders. In the 1970s, the United States declared a "war on drugs", considering drug-trafficking a menace to its national security. Policy since then has reinforced repressive measures along US borders and has driven the involvement of militaries in the combat against drug-trafficking in Latin America. Despite the increase of illegal drug production and consumption, the militarized approach has been maintained, generating great violence and transborder conflicts. The article presents a brief political history of the militarization of policies on drug trafficking, highlighting their effects in Colombia, Mexico and Brazil.

Keywords: Drug-trafficking - War on Drugs - Latin-America - United States 